\title{
Iron Uptake Processes in Mycobacterium vaccae R877R, a Mycobacterium Lacking Mycobactin
}

\author{
By ANN J. M. MESSENGER, $\dagger$ RICHARD M. HALL AND COLIN \\ RATLEDGE* \\ Department of Biochemistry, University of Hull, Hull HU6 $7 R X, U K$
}

(Received 1 July 1985)

\begin{abstract}
The production of exochelins (MV) was established in Mycobacterium vaccae $\mathrm{R} 877 \mathrm{R}$ under irondeficient conditions in concentrations about five times greater than in Mycobacterium smegmatis. $M$. vaccae does not produce mycobactin nor is salicylic acid secreted into the medium. A simple method is described using ${ }^{55} \mathrm{Fe}$-labelled culture filtrates for assessing exochelin production and which would be applicable to other mycobacteria. One of the exochelins produced (MV3) is part of an active iron uptake system and another (MV1) is responsible for a passive uptake system. MV3 exochelin has similar chromatographic properties and biological activity to the major exochelin produced by $M$. smegmatis: iron uptake from MV3 exochelin was inhibited by dinitrophenol, $\mathrm{NaN}_{3}$ and $\mathrm{HgCl}_{2}$, and was judged to be an active transport process. This process was not inhibited by equimolar amounts of ferri-salicylate or ferri-citrate both of which could be used separately as sources of iron for the organism. Uptake from these latter sources was insensitive to metabolic inhibitors and uncouplers. The multiplicity of pathways for iron uptake in a single organism is discussed.
\end{abstract}

\section{INTRODUCTION}

Studies on iron transport in mycobacteria have so far concentrated on Mycobacterium smegmatis due to its rapid growth and lack of pathogenicity. Four systems of iron transport have been reported. Exochelin, which is produced as a bacterial siderophore in the culture filtrate under iron-deficient conditions, complexes with any available iron to form ferriexochelin (Macham et al., 1977) and transports iron into the cell by two uptake processes: (i) a highaffinity system operating at low concentrations of iron and (ii) a low-affinity system which operates at higher $(>10 \mu \mathrm{M})$ concentrations of iron. The first process is energy-dependent, the second is passive (Stephenson \& Ratledge, 1979). The third system for iron uptake is via ferric salicylate, which can transport iron into the cells under iron-deficient conditions, but its role is restricted, because this system does not operate in the presence of phosphate (Ratledge $e t$ al., 1974). Nevertheless, salicylate (or 6-methylsalicylate) has been recognized as an extracellular product in iron-deficient mycobacteria (see Ratledge, 1982) though its occurrence may be due to overproduction as a precursor of the aromatic moiety of mycobactin (see below). The fourth process which has been described is via ferric dicitrate (Messenger \& Ratledge, 1982). In addition to exochelin and salicylic acid, $M$. smegmatis also produces large quantities of mycobactin (up to $10 \%$ of the dry cell weight) within the cell under iron-deficient conditions. Mycobactin is a lipid-soluble siderophore and its role in iron uptake is considered to be that of a storage mechanism for iron, but it is able to donate iron into the cells by an unspecified process (Ratledge, 1982; McCready \& Ratledge, 1979).

$\dagger$ Present address: The Protein Laboratory, 34 Sigurdsgade, DK-2200 Copenhagen N, Denmark. 
Our interest in Mycobacterium vaccae was first aroused during a survey of mycobactin production in rapidly-growing mycobacteria (Hall \& Ratledge, 1984). Unlike other species it produced no discernible mycobactin under a variety of different growth conditions and so the question of how its iron uptake differed from mycobactin-producing strains arose. The nutritional disadvantage that may therefore accrue to $M$. vaccae not possessing mycobactin has been considered separately (Hall \& Ratledge, 1986).

Iron transport is considered to be important in determining the pathogenicity of microorganisms (Weinberg, 1978; Bullen, 1981). Since many mycobacteria are pathogenic, the study of their iron transport may have some bearing on control of diseases caused by these species. $M$. vaccae is of particular interest because of a suggested taxonomic link with Mycobacterium leprae, which cannot be cultivated on synthetic medium (Stanford et al., 1975). The study of $M$. vaccae may, therefore, add to our knowledge of $M$. leprae and of the reasons for the difficulty in cultivating this species in the laboratory.

In this paper we describe the production of exochelin siderophores in $M$. vaccae $\mathrm{R} 877 \mathrm{R}$ and discuss their similarity to those produced by $M$. smegmatis. The method used to find exochelins in $M$. vaccae was a simple radiolabelling technique which could be used as a rapid method for screening other mycobacterial cultures for exochelin production. The possible roles of citrate and of salicylate, even though the latter compound is not produced by $M$. vaccae, are also investigated to complete our knowledge of iron transport processes in this species.

\section{METHODS}

Organisms and growth. M. vaccae strain R877R (from Dr J. R. Stanford, Middlesex Hospital Medical School, London, UK) and M. smegmatis NCIB 8548 were grown with shaking at $37^{\circ} \mathrm{C}$ on glycerol/asparagine $/ \mathrm{mineral}$ salts medium as previously described (Ratledge \& Hall, 1971). Iron-deficient cultures contained $0.02 \mu \mathrm{g} \mathrm{Fe} \mathrm{ml}^{-1}$ and iron-sufficient cultures $2 \cdot 0 \mu \mathrm{g} \mathrm{Fe} \mathrm{ml}^{-1}$.

Isolation of exochelin and estimation of exochelin production. Exochelins were isolated as described previously (Macham et al., 1977) with certain minor modifications. The medium, after addition of $\mathrm{FeCl}_{3}$, was mixed with Zerolit 225 (SRC 16), and filtered through Whatman no. 1 filter paper. The exochelins were extracted from the resin by adding batches of eluting buffer $\left(\mathrm{NH}_{4} \mathrm{OH}_{7}^{\prime} \mathrm{NH}_{4} \mathrm{Cl}\right.$ buffer, $\left.\mathrm{pH} 9 \cdot 5\right)$, stirring for 10 min and filtering again.

Time course ${ }^{55} \mathrm{FeCl}_{3}$-labelling of iron-binding compounds in culture medium. Samples of culture were filtered through GF/C filter paper and to $1 \mathrm{ml}$ of the filtrate was added $10 \mu \mathrm{l}{ }^{55} \mathrm{FeCl}_{3}$ (Amersham) containing $2.75 \mu \mathrm{g}$ $\mathrm{Fe}[\mathrm{l} \mu \mathrm{Ci}(37 \mathrm{kBq})$ per $\mu \mathrm{g} \mathrm{Fe}]$ or $50 \mu \mathrm{l}{ }^{55} \mathrm{FeCl}_{3}$ containing $41 \cdot 2 \mu \mathrm{g} \mathrm{Fe}[1 \mu \mathrm{Ci}(37 \mathrm{kBq})$ per $\mu \mathrm{g} \mathrm{Fe}]$. The lower amount of iron was insufficient to saturate all iron-binding potential of the culture filtrate and would therefore bind to the compound with the highest affinity for iron, whereas the higher amount of iron was calculated to be sufficient to saturate all iron-binding compounds. In this way the strongest iron-binding compound in the exochelins present could be identified.

The labelled samples were fractionated by cation-exchange column chromatography using AG50W-X4 (BioRad), 200-400 mesh, $\mathrm{NH}_{4}^{+}$-form, $250 \times 15 \mathrm{~mm}$, eluting with a gradient of $0 \cdot 1 \mathrm{M}-\mathrm{NH}_{4} \mathrm{OH} /$ acetic acid, $\mathrm{pH} 6$, to $1 \mathrm{M}-\mathrm{NH}_{4} \mathrm{OH} /$ acetic acid, $\mathrm{pH} 9$ (cf. Macham et al., 1977). ${ }^{55} \mathrm{Fe}$ was assayed in $500 \mu \mathrm{l}$ samples taken from each fraction.

Uptake studies of ${ }^{55} \mathrm{Fe}$ from ferriexochelin. Desferriexochelins were prepared, and labelling with ${ }^{55} \mathrm{FeCl}_{3}$ was done, as previously described (Macham et al., 1977). Uptake studies were done as described by Stephenson \& Ratledge (1979) using cells suspended in Tris/ $\mathrm{HCl}(50 \mathrm{~mm}) \mathrm{pH} 7.1$ buffer. Radioactive ${ }^{55} \mathrm{Fe}$ was assayed as described below.

Assay of ${ }^{55} \mathrm{Fe}$. ${ }^{55} \mathrm{Fe}$ was estimated by liquid scintillation counting using one of two systems. (i) The $500 \mu \mathrm{l}$ samples from the time course study were placed in plastic scintillation vials and $10 \mathrm{ml}$ scintillation fluid, containing per litre $724 \mathrm{ml}$ xylene, $176 \mathrm{ml}$ Triton $\mathrm{N} 101$ and $10 \mathrm{~g}$ butyl PBD, was added. (ii) Filter papers from uptake studies were oven-dried in glass scintillation vials and $1 \mathrm{ml}$ Soluene (Packard) was added; the vials were incubated at $50{ }^{\circ} \mathrm{C}$ for $5 \mathrm{~h}$ and then $50 \mu \mathrm{l}$ glacial acetic acid was added, followed by $10 \mathrm{ml}$ scintillation fluid ( $100 \mathrm{~g}$ naphthalene, $10 \mathrm{~g}$ PPO made up to 1 litre with toluene).

Standard solutions of ${ }^{55} \mathrm{Fe}$ were used to calculate the amounts of iron present.

Iron uptake with salicylate and citrate. These were done as described by Stephenson \& Ratledge (1979) and Messenger \& Ratledge (1982) with some minor modifications. In uptake studies with ${ }^{55} \mathrm{Fe}-\mathrm{salicylate}, 0 \cdot 1 \mathrm{M}-$ Tris/HCl buffer was used instead of phosphate buffer, which precipitates iron in this system. ${ }^{55} \mathrm{Fe}-$ Salicylate was prepared at an Fe: salicylate molar ratio of $1: 3 ;{ }^{55} \mathrm{Fe}$-dicitrate was prepared at an Fe:citrate ratio of $1: 200 .{ }^{55} \mathrm{Fe}$ was assayed by liquid scintillation counting as described previously (Stephenson \& Ratledge, 1979). 
RESULTS

Time course study of siderophore production in $M$. vaccae

Using the saturation ${ }^{55} \mathrm{FeCl}_{3}$-labelling technique of culture filtrates taken from an irondeficient culture of $M$. vaccae, it was possible to separate three main iron-binding peaks (see Fig. 1) using a cation-exchange chromatography system similar to that used previously in fractionating exochelins from $M$. smegmatis (Macham et al., 1977). These fractions were designated 1 ( 5 to $30 \mathrm{ml}$ ), 2 (90 to $120 \mathrm{ml}$ ) and 3 (190 to $240 \mathrm{ml}$ ). Production of each siderophore was detected at day 3 of growth; the production of fraction 3 reached a maximum at day 7 and stayed at a steady concentration until day 10 . Increased production of fraction 1 did not begin until day 7 and continued to rise to day 10. Fraction 2 also increased from day 7 to 10 .

When similar samples of culture filtrates were labelled with non-saturating amounts of ${ }^{55} \mathrm{FeCl}_{3}$, peak 3 predominated throughout the time course, showing that it had a higher affinity for iron than the other peaks (see Fig. 1, which gives the results for the samples taken after 7 and $10 \mathrm{~d}$; earlier samples are not shown only for the sake of simplicity).

No siderophores of any description were seen when $M$. vaccae was grown under ironsufficient conditions.

When a similar experiment was done with $M$. smegmatis, ${ }^{55} \mathrm{Fe}$ was associated with similar fractions although the same amount of culture filtrate bound about only $20 \%$ of the ${ }^{55} \mathrm{Fe}$. The fraction in $M$. smegmatis which corresponded to fraction 3 in $M$. vaccae was the major exochelin which was active in the transport of iron into the cell (Stephenson \& Ratledge, 1979).

\section{Identification of ${ }^{55} \mathrm{Fe}$-binding peaks from $\mathrm{M}$. vaccae as exochelins}

Once the presence of ${ }^{55} \mathrm{Fe}$-binding compounds under iron-deficient growth conditions had been established, the procedure for exochelin extraction and fractionation was done in bulk using 7-d-old cultures. $A_{430}$ for such culture filtrates was between 0.44 and 0.51 , approximately five times the maximum value observed with culture filtrates from $M$. smegmatis.

Peaks of absorbance at $430 \mathrm{~nm}$ characteristic of exochelins were found to correspond, on cation-exchange chromatography, to the ${ }^{55} \mathrm{Fe}$ peaks found during the time course study. Fraction 1 not only bound much iron (see Fig. 1) but also had a high $A_{260}$ value compared with its $A_{430}$ value (approximately 10:1). This is not characteristic of other exochelins and this fraction was considered to be a mixture of neutral and anionic compounds as it eluted in the void volume. It was not fractionated further before beginning biological studies. The three fractions of exochelin were designated MV1, MV2 and MV3 exochelins, following the nomenclature devised for prefixing the exochelins from $M$. smegmatis as 'MS' (Macham \& Ratledge, 1975). The elution values of fractions 2 and $3 \mathrm{MV}$ exochelins corresponded to the MS exochelins and may be similar or even identical in each organism.

\section{Uptake of ${ }^{55} \mathrm{Fe}$ from $\mathrm{MV}$ exochelins}

Because of the strong chromatographic similarities of the exochelins from $M$. vaccae and $M$. smegmatis, uptake studies were done using both types of exochelin into both species. The emphasis of this work was, though, with the MV exochelins.

Uptake of ${ }^{55} \mathrm{Fe}$ from MV1 exochelin at $1 \mu \mathrm{M}$ (Fig. $2 a$ ) occurred at similar rates into both $M$. vaccae and $M$. smegmatis. Metabolic inhibitors, DNP $(200 \mu \mathrm{M}), \mathrm{HgCl}_{2}(100 \mu \mathrm{M})$, or $\mathrm{NaN}_{3}$ $(30 \mathrm{~mm})$ had no effect on either process (results not shown). There was no uptake of ${ }^{55} \mathrm{Fe}$ from MV2 exochelin at $1 \mu \mathrm{M}$ or $10 \mu \mathrm{M}$ into $M$. vaccae. This exochelin was judged to be biologically inactive and was not examined further. Uptake of ${ }^{55} \mathrm{Fe}$ from MV3 exochelin occurred at an appreciable rate into $M$. vaccae when it was at $10 \mu \mathrm{M}$ (Fig. $2 b$ ) though no significant uptake was observed at $1 \mu \mathrm{M}$ (results not shown). This uptake was much more rapid into cells grown with iron-deficiency than ones grown with a sufficiency of iron, and was, moreover, strongly inhibited by DNP, $\mathrm{NaN}_{3}$ and $\mathrm{HgCl}_{2}$ (Fig. 2c). When the equivalent exochelin from $M$. smegmatis (i.e. MS3) was used in iron uptake in $M$. vaccae, the rate of uptake was the same as that of MV3 (Fig. 2b). 


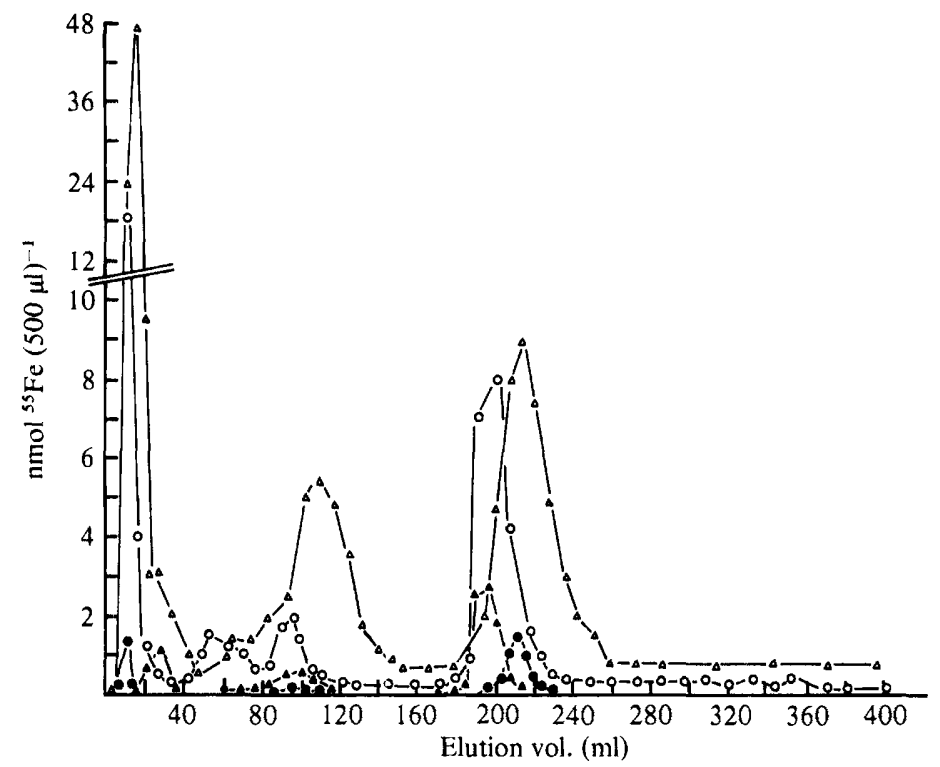

Fig. 1. Time course study of the iron-binding capacity of culture medium from $M$. vaccae grown with iron-deficiency. Iron-binding in $1 \mathrm{ml}$ samples of culture medium was estimated with $41 \cdot 2 \mu \mathrm{g}{ }^{55} \mathrm{Fe}$ added $(\mathrm{O}, 7 \mathrm{~d} ; \Delta, 10 \mathrm{~d})$ and $2.75 \mu \mathrm{g}{ }^{55} \mathrm{Fe}$ added $(O, 7 \mathrm{~d}, \boldsymbol{\Delta}, 10 \mathrm{~d})$. Fractionation was by ion-exchange chromatography with a gradient of 0.1 to $1 \mathrm{M}-\mathrm{NH}_{4}^{+}, \mathrm{pH} 6$ to 9 . Results are from a representative experiment of 2 determinations.

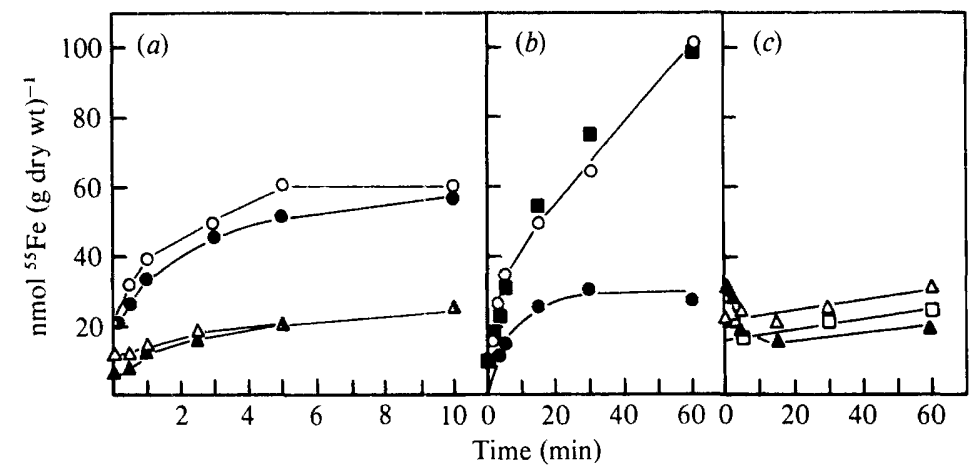

Fig. 2. (a) Uptake of ${ }^{55} \mathrm{Fe}$ from MV1 exochelin $(1 \mu \mathrm{M})$ into $M$. vaccae $(O, \Delta)$ and $M$. smegmatis $(\mathbf{O}, \mathbf{\Delta})$ cells grown with iron-deficiency $(O, O)$ or iron-sufficiency $(\Delta, \Delta)$.

(b) Uptake of ${ }^{55} \mathrm{Fe}$ from MV3 exochelins $(10 \mu \mathrm{M})$ into $M$. vaccae cells grown with iron-deficiency $(\mathrm{O})$ or iron-sufficiency $(\bigcirc)$. Uptake was also measured from MS exochelin $(10 \mu \mathrm{M})$ into iron-limited $M$.

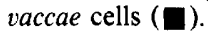

(c) Effect of potential inhibitors, DNP $(200 \mu \mathrm{M})(\Delta)$, sodium azide $(30 \mathrm{mM})(\Delta)$ and mercuric chloride $(0 \cdot 1 \mathrm{mM})(\square)$, on ${ }^{55} \mathrm{Fe}$ uptake from MV3 exochelins $(10 \mu \mathrm{M})$ into iron-limited $M$. vaccae cells.

Results are from a representative experiment of 3 determinations.

This parallel between MS3 and MV3 exochelins was reinforced when both were used at $1 \mu \mathrm{M}$ with comparable rates for iron uptake observed into $M$. smegmatis (Fig. 3), though the absolute rates were much higher than those into $M$. vaccae, where it had not been possible to observe a significant uptake using exochelins at $1 \mu \mathrm{M}$.

The uptake of ${ }^{55} \mathrm{Fe}$ from MV3 exochelin (at $10 \mu \mathrm{M}$ ) was not affected by the addition of equimolar ferri-salicylate or ferri-citrate though when these were added at $100 \mu \mathrm{M}$ there was about $75 \%$ inhibition of uptake as measured over $30 \mathrm{~min}$. 


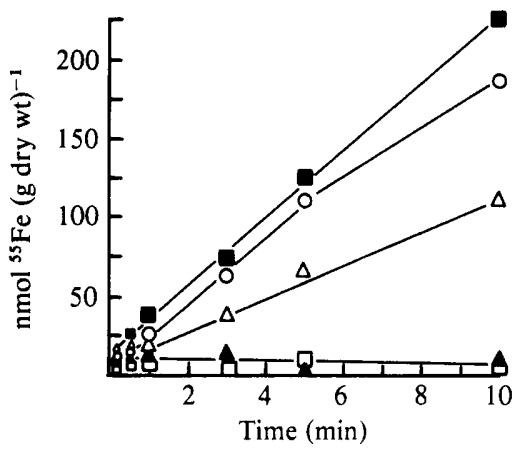

Fig. 3

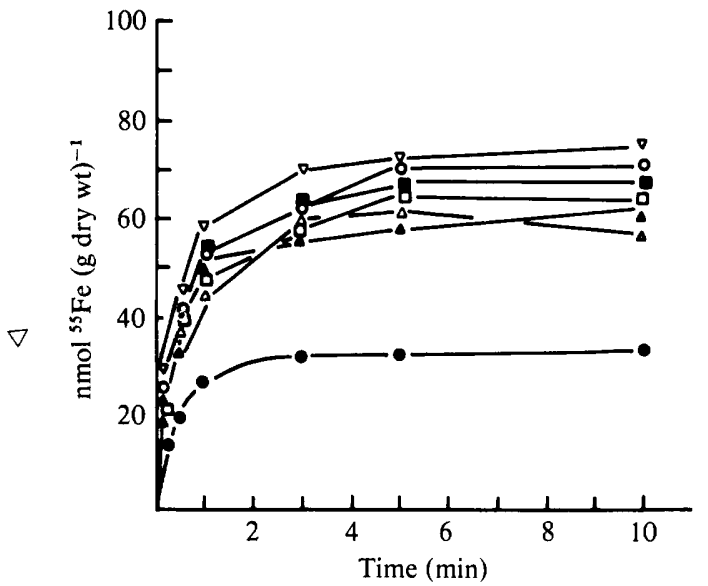

Fig. 4

Fig. 3. Uptake of ${ }^{55} \mathrm{Fe}$ from MV3 exochelins $(1 \mu \mathrm{M})$ into $M$. smegmatis cells grown under ironlimitation $(O)$, and effect of a range of potential inhibitors, DNP $(200 \mu \mathrm{M})(\triangle)$, sodium azide $(30 \mathrm{mM})$ (A) and mercuric chloride $(0 \cdot 1 \mathrm{mM})(\square) .{ }^{55} \mathrm{Fe}$ uptake was also measured from MS3 exochelin $(1 \mu \mathrm{M})$ (a) into iron-limited $M$. smegmatis cells. Results are from a representative experiment of 3 determinations.

Fig. 4. Uptake of ${ }^{55} \mathrm{Fe}$ from ${ }^{55} \mathrm{Fe}$-salicylate into $M$. vaccae cells grown with iron-deficiency $(O)$ and iron-sufficiency $(O)$, and also in the presence of a range of potential inhibitors, DNP $(200 \mu \mathrm{M}(\triangle)$, sodium azide (30 mM) (A), sodium cyanide $(10 \mathrm{mM})(\square)$, CCCP $(0.1 \mathrm{mM})(\square)$ and mercuric chloride $(0.1 \mathrm{mM})(\nabla) .{ }^{55} \mathrm{Fe}$ was present at $1 \mu \mathrm{M}$ in the uptake system at a molar ratio of $1: 3$ with salicylate. Results are from a representative experiment of 3 determinations.

\section{Other uptake systems for iron acquisition by $M$. vaccae}

$M$. vaccae R877R, when previously examined for mycobactin content (Hall \& Ratledge, 1984), was devoid of mycobactin. The bacterium also failed to produce salicylate, which constitutes the aromatic nucleus of mycobactin (Snow, 1970), and which occurs in the free state in culture filtrates of other mycobacteria up to $30 \mu \mathrm{g} \mathrm{ml}^{-1}$. Nevertheless, iron was taken up from ${ }^{55} \mathrm{Fe}$-salicylate (Fig. 4) as well as from ${ }^{55} \mathrm{Fe}$-citrate (Fig. 5) into $M$. vaccae with higher rates of uptake being observed with cells grown with iron-deficiency than with those grown with ironsufficiency. Iron uptake from both salicylate and citrate was insensitive to a range of metabolic inhibitors: $\mathrm{NaN}_{3}$; DNP, CCCP, $\mathrm{NaCN}$ and $\mathrm{HgCl}_{2}$. Uptake from citrate was slowed when the assay was done at $4{ }^{\circ} \mathrm{C}$ (Fig. $5 a$ ): this experiment was not done with ${ }^{55} \mathrm{Fe}$-salicylate. There was no uptake of iron from ${ }^{55} \mathrm{Fe}$ EDTA into either organism.

When uptakes from ${ }^{55} \mathrm{Fe}$-salicylate or ${ }^{55} \mathrm{Fe}$-citrate were assayed at $1 \mu \mathrm{M}$ in the presence of equimolar amounts of each other, but with unlabelled iron, there was no significant diminution of the rates of uptake (results not shown). Competition experiments involving higher concentrations of the unlabelled iron complex were not done.

\section{DISCUSSION}

The production of exochelins by $M$. vaccae under iron-deficient growth conditions in much greater quantities than are found with $M$. smegmatis is offset by the lower efficiency of iron transport into $M$. vaccae cells. As the principal exochelin of both organisms (MV3 and MS3) appears to be similar, judging by their identical chromatographic behaviour and by their interchangeability between uptake assays with $M$. smegmatis and $M$. vaccae, it was concluded that the difference in the rates of iron uptake was due to a difference in cell composition between the two organisms. The fact that $M$. vaccae does not possess mycobactin is probably of no significance in this respect, as mycobactin is not involved in uptake of iron from exochelin in $M$. smegmatis (Stephenson \& Ratledge, 1979). One might expect mycobactin, as a potential store of 


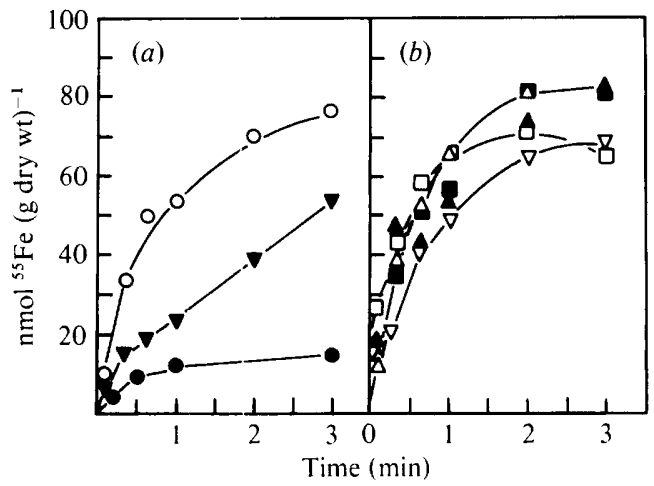

Fig. 5. (a) Uptake of ${ }^{55} \mathrm{Fe}$ from ${ }^{55} \mathrm{Fe}$-citrate into $M$. vaccae grown with iron-deficiency $(O)$ and ironsufficiency ( $)$ and also the former at $4{ }^{\circ} \mathrm{C}(\boldsymbol{\nabla}) .{ }^{55} \mathrm{Fe}$ was present at $1 \mu \mathrm{M}$ in the uptake system at a molar ratio of $1: 200$ with citrate.

(b) Uptake of ${ }^{55} \mathrm{Fe}$ from ${ }^{55} \mathrm{Fe}$-dicitrate into $M$. vaccae cells grown with iron-deficiency and in the presence of a range of potential inhibitors, $\operatorname{DNP}(200 \mu \mathrm{M})(\triangle)$, sodium azide $(30 \mathrm{mM})(\mathbf{\Delta})$, sodium cyanide $(10 \mathrm{~mm})(\square)$, CСCP $(0 \cdot 1 \mathrm{mM})(\square)$ and mercuric chloride $(0 \cdot 1 \mathrm{mM})(\nabla)$.

Results are from a representative experiment of 3 determinations.

iron, to become increasingly involved in iron assimilation as the concentration of iron presented to the cells was increased. Instead a very slow rate of iron uptake was observed with ferriexochelin at $1 \mu \mathrm{M}$ when compared to that at $10 \mu \mathrm{M}$. A more likely explanation is that the components of the active transport system for exochelin MV3 are at a lower activity or amount in $M$. vaccae cells than in $M$. smegmatis (that it is an active transport system is shown by its sensitivity to various inhibitors). This is reflected in the considerable differences seen between cells of both species grown with iron-deficiency and iron-sufficiency with regard to exochelinmediated iron transport. Such differences would again argue in favour of a minimal involvement of mycobactin as there is no mycobactin present in $M$. vaccae under any growth conditions, and so if lack of mycobactin was a key factor, there should be only a slight difference between the two types of cell. Instead, we deduce that the various components involved in iron uptake, including the proteins for exochelin biosynthesis, are strongly repressed in cells grown with iron sufficiency and this is the reason for the diminished rate of iron uptake in these cells.

It is unlikely that the lower rate of iron uptake into $M$. vaccae, when compared with that into $M$. smegmatis, causes it to have a slower growth rate. No evidence has yet been obtained with any mycobacterium that iron uptake is a growth rate-controlling process (Ratledge, 1982, 1984). A more probable explanation is that the slower growth rate of $M$. vaccae has led to the evolution of a slower iron uptake rate: the components of the exochelin uptake system becoming adjusted to acquiring iron for cells at a rate approximately matching their demand. The question of whether M. vaccae suffers any nutritional disadvantage because of its lack of mycobactin under any condition is a separate issue to the mechanisms by which it acquires iron, and has been investigated separately (Hall \& Ratledge, 1986).

The number of iron uptake mechanisms found here in $M$. vaccae and previously in $M$. smegmatis (Stephenson \& Ratledge, 1979; Messenger \& Ratledge, 1982) is comparable with those in Escherichia coli, where at least five independent mechanisms exist (Hartmann \& Braun, 1981). This diversity may be necessary for adaptation so that the micro-organisms can acquire iron under varied growth conditions. Each uptake system may function only under a narrow set of conditions.

The multiplicity of exochelins has already been commented on with respect to $M$. smegmatis (Stephenson \& Ratledge, 1979) and there is clearly more than one present in culture filtrates of $M$. vaccae. However, it is possible that there is only one biologically active molecule in each cell, with the others arising by various biochemical modifications, such as acetylations, as growth progresses. With $M$. vaccae, for example, formation of MV1 and MV2 exochelins was 
appreciable after the amount of MV3 had reached a plateau. Exochelin-mediated iron transport may be by one or both of two routes according to the concentration presented to the cell (Stephenson \& Ratledge, 1979), but under physiological conditions, the high-affinity active process may be assumed to be the key one.

The uptake of iron from ferri-citrate could be of possible significance for the in vivo uptake of iron where citrate could be available from, and within, host tissues and macrophages. The significance of iron uptake from ferri-salicylate is less certain to have a role in vivo, although salicylate appears to be over-produced by all mycobacteria which elaborate a mycobactin. However, the presence of such an uptake system in $M$. vaccae, which produces neither salicylate nor mycobactin, is an unexpected finding and may suggest that a novel uptake route exists in $M$. vaccae. Our previous work indicated that the recipient molecule for iron uptake from salicylate was mycobactin itself (Marshail \& Ratledge, 1972). The ferri-salicylate route of iron uptake is not a general iron-specific process, since a complex such as ferri-EDTA is not utilized by this organism. However, micro-organisms can acquire iron from various sources which they have not elaborated: for example, $E$. coli can acquire iron from ferri-ferrichrome and produces specific outer membrane proteins for such a function (Luckey et al., 1975).

In conclusion, $M$. vaccae appears to be similar to $M$. smegmatis in elaborating exochelins with similar characteristics. The principal biologically active exochelin from each organism cannot be distinguished and may be identical. Alternative routes for iron assimilation, via salicylate and citrate, occur in $M$. vaccae as they do in $M$. smegmatis although the exact mechanism of uptake remains uncertain in view of the absence of mycobactin in $M$. vaccae. The lack of mycobactin does not appear to have produced any radical change in iron uptake mechanisms, and the necessity for a mycobacterium to elaborate a mycobactin must be presumed to be an environmental one (which would include the ability to grow within animal tissues) rather than it fulfilling any useful function under laboratory growth conditions.

A.J.M.M. was supported by a research grant from the SERC and R.M.H. by a grant from the Medical Research Council.

\section{REFERENCES}

Bullen, J. J. (1981). The significance of iron in infection. Reviews of Infectious Diseases 3, 11271138.

Hall, R. M. \& Ratledge, C. (1984). Mycobactins as chemotaxonomic characters for some rapidly-growing mycobacteria. Journal of General Microbiology 130, 1883-1892.

Hall, R. M. \& Ratledge, C. (1986). Mycobactin and the competition for iron between two species of mycobacterium, $M$. neoaurum and $M$. raccae. Journal of General Microbiology 132, 839-843.

Hartmann, A. \& Braun, V. (1981). Iron uptake and iron-limited growth of Escherichia coli K-12. Archices of Microbiology 130, 353-356.

LUCKey, M., Wayne, R. \& NeIlandS, J. B. (1975). In vitro competition between ferri-chrome and phage for the outer membrane T5 receptor complex of Escherichia coli. Biochemical and Biophysical Research Communications 64, 687-693.

Macham, L. P. \& Ratledge, C. (1975). A new group of water-soluble iron-binding compounds from mycobacteria: the exochelins. Journal of General Microbiology 89, 379-382.

Macham, L. P., Stephenson, M. C. \& Ratledge, C. (1977). Iron transport in Mycobacterium smegmatis: the isolation, purification and function of exochelin MS. Journal of General Microbiolog! 101, 41 49
Marshall, B. J.\& Ratledge, C. (1972). Salicylic acid biosynthesis and its control in Mycohacterium smegmatis. Biochimica et biophysica acta 264, 106-116.

McCready, K. A. \& Ratledge, C. (1979). Ferrimycobactin reductase activity from Mycobacterium smegmatis. Journal of General Microbiology 113, 6772.

Messenger, A. J. M. \& Ratledge, C. (1982). Iron transport in Mycohacterium smegmatis: uptake of iron from ferric citrate. Journal of Bacteriolog. 149, 131-135.

RATLEDGE, C. (1982). Nutrition, growth and metabolism. In The Biology of the Mycohacteria, vol. 1, pp. 185-271. Edited by C. Ratledge \& J. L. Stanford. London: Academic Press.

RATLEDGE, C. (1984). Metabolism of iron and other metals by mycobacteria. In The Mycobacteria - A Source Book, part A, pp. 603-627. Edited by G. P. Kubica \& L. G. Wayne. New York: Marcel Dekker.

RATLEDGE, C. \& HALL, M. J. (1971). Influence of metal ions on the formation of mycobactin and salicylic acid in Mycobacterium smegmatis grown in static culture. Journal of Bacteriology 108, 312-319.

Ratledge, C., Macham, L. P., Brown, K. A. \& Marshall, B. J. (1974). Iron transport in Mycobacterium smegmatis: a restricted role for salicylic acid in the extracellular environment. Biochimica et biophysica acta 372, 39-51. 
SNow, G. A. (1970). Mycobactins: iron-chelating growth factors from mycobacteria. Bacteriological Reviews 34, 99-125.

Stanford, J., Rook, G. A. W., Convit, J., Godal, T., Kronvall, G., Rees, R. J. W. \& Walsh, G. P (1975). Preliminary taxonomic studies on the leprosy bacillus. British Journal of Experimental Pathology 56, 579-585.
Stephenson, M. C. \& Ratledge, C. (1979). Iron transport in Mycobacterium smegmatis: uptake of iron from ferri-exochelin. Journal of General Microbiology 110, 193-202.

WeINBERG, E. D. (1978). Iron and infection. Micrcbiological Reviews 42, 45-66 